\title{
COOPERATIVE MODELS FOR INFORMATION TECHNOLOGY TRANSFER IN THE CONTEXT OF OPEN INNOVATION
}

\author{
Gonzalo León \\ Technical University of Madrid \\ Madrid, Spain
}

\begin{abstract}
Universities and public research institutions (PROS) are increasingly required to address strategic needs defined by industrial sectors both from the education and research standpoint and contribute more intensively to the absorption of advanced technologies. Many countries rely on the reform of traditional structures of universities and PROs by creating specific centers of excellence to ensure long-term partnerships with industry. The need for stable universityindustry partnerships focuses on the evolution from short-term instruments to long-term instruments for cooperation in the wider context of technology transfer (TT) embedded in technology development processes. Within this context, governments are looking for adequate policy instruments to offer more attractive funding conditions to increase institutional involvement in TT as a pre-requirement to increase the long-term stability of public-private partnerships.

The specific situation in the European Union is addressed where steps toward fostering open innovation have been taken to overcome structural, institutional, and cultural rigidities. The analysis is focused on the short and long term instruments provided by the European Framework Program and other European initiatives. Specialized technology transfer structures, especially those targeting the creation of joint research centers, are among the most common approaches in the EU in order to facilitate the exchange of tacit and explicit knowledge and accelerate innovation.

The rationale behind the concept of open innovation applied to technology transfer and diffusion activities is addressed. Interest is focused on the identi-
\end{abstract}

Please use the following format when citing this chapter:

León, G., 2007, in IFIP International Federation for Information Processing, Volume 235, Organizational Dynamics of Technology-Based Innovation: Diversifying the Research Agenda, eds. McMaster, T., Wastell, D., Ferneley, E., and DeGross, J. (Boston: Springer), pp. 43-61. 
fication of trends, drivers, and limits in the models used today for TT and their impact on the design of policy. From this analysis, new open models emerge for immature technologies where research and TT cannot be isolated.

Finally, although these elements can be found in any science and technology domain, information technologies offer a set of special features making it even more important to address TT activities in a cooperative way where universities facilitate the transference of immature technologies. Experiences on the deployment of grid services will be outlined in this context. This case illustrates the benefits of a close open cooperation amongst all stakeholders (industry, academia, and governments) to support TT and to speed up grid services deployment.

\section{INTRODUCTION}

The assumption that scientific and technical knowledge is increasingly generated, transferred, and diffused in socio-technical networks composed by different types of agents (both public and private institutions) is widely accepted by governments and institutions in all advanced countries (Albino et al. 2005; COM 2006b; Foray 2005b; Ormala et al. 2005). Individual entities no longer possess in-house all of the required knowledge to develop new, advanced, complex products and processes; it is necessary to create the right context to efficiently generate and share knowledge with potential allies (both public and private) in order to speed up technological innovation. As a consequence, governments are focusing their research and innovation policies and instruments on this new scenario. Institutional reforms in public systems are also pursuing the same strategy.

The transference of technical knowledge commonly known as technology transfer ${ }^{1}$ (TT), has been usually described as a bilateral interaction between one entity acting as provider of the technical knowledge and another acting as receiver. Models for TT rely on the assumption that provider entities possesses all of the knowledge they need to support technology development and transference, while receivers select a single entity as provider for the required technology. Models have ben refined to cover specialized roles based on the inclusion of TT broker entities (Geroski 2000) and other complementary activities to facilitate the transference of tacit knowledge. A common but hidden assumption is that the technology to be transferred is mature enough to support a linear process where the technology does not need to be substantially modified during the transference process; TT is delayed until reaching a determined technology maturity level. Technology adaptation only comes from the adequacy of the use of the technology to the receiver's specificities and in its merging with other preexisting technologies.

Unfortunately, real scenarios are far from this ideal situation. It is more common to find a situation where technologies are developed by different partners and responsibility for integration into products, systems, or services. falls on the partners, with responsibilities spread over a complex network. In this context, TT and even final deployment

'Although the use of the term knowledge transfer seems more adequate to cope with other nontechnical aspects, technology transfer is used in this article to emphasize the transfer of technical knowledge. 
processes start with immature technologies. TT is progressively embedded in complex innovation processes involving new technologies, new user communities, and new applications fields. To cope with this additional complexity, a more cooperative scenario, with additional contributing partners, learning processes, and feedback mechanisms, is required to reduce the associated risks.

Models to explain the complexity of the interactions in socio-technical networks are also becoming more complex. The work on clusters (Albino et al. 2005) and science parks has developed richer scenarios with different types of partner entities: leader firm, follower, subcontractor, manufacturing technology source, infrastructure supplier, client/ user, university/research center, etc., each with different roles and responsibilities. Based on this, it is possible to analyze roles, information flows, and dynamic interactions where geographical proximity is only one factor among many.

Not all of the partners categories mentioned above play the same role in accelerating technical innovation. Universities, as basic agents of knowledge-based processes, could play a crucial role in the transference of immature technologies by emphasizing cooperation with industry and government. This was, in fact, the basis of the well-known triple helix model (Etzkowitz and Leysderdoff 2000), which has strongly influenced research, innovation policy design, and the role of the university in the last decade, and the subsequent need to extend it to TT activities. This is the basis for the policy trend to "open innovation" and the emphasis paid to knowledge sharing.

Within the context of open innovation, this paper will analyze the cooperation models used today paying attention to TT requirements. The recognition of the need to develop open cooperative technology transfer models is the basis for the approach addressed here. The analysis of the role of public research entities (PROs) and universities in immature TT activities will be addressed. This focus will allow describing the different types of policy instruments available today and institutional involvement in the European Union. Emphasis will be paid to long-term, stable partnerships, where TT can be addressed within a long time horizon. Although the analysis could be applied to all industrial sectors, the information technologies (IT) will be addressed specifically to tune the proposed models.

\section{THE EVOLVING NATURE OF RESEARCH AND DEVELOPMENT AT THE PRIVATE SYSTEM}

\subsection{Challenges for the Innovation Process}

Enterprises need to become competitive in a globalized world; this competitiveness goal relies on innovation to be sustainable. Today, private companies are challenged in their innovative processes due to three complementary factors.

1. The need to cope with multidisciplinary approaches to deal with system complexity. Speeded up by emerging technology convergence (i.e., in the emerging field of bionano-cogno), requirements for large system design, and new application fields, the probability of basing new products on technologies available in-house is very low. It seems better to join forces with other institutions if partnership for specific purposes can be created in a relatively short time. 
2. The need to create and to deliver solutions for real or potential customers in shorter periods of time. Due to the faster pace of technological change, the need to anticipate future customers' needs with in-house personnel becomes a huge barrier that avoids relying in the use of internal teams for complex product development. As a consequence, immature technologies should be exposed to selected users in order to trigger feedback and to speed up maturation. Solutions also require closer interactions with users than in the past to cope with multicultural diversity challenges and trigger mutual learning processes.

3. The need to increase organizational flexibility to reduce costs and to adapt the company to new markets and regulations. The consequence is a rich emergence of more agile organizations where core businesses (with some previously identified key technologies) are retained while other non-crucial aspects are externalized. Under this approach, companies intend to identify what are or should be the key knowledge they must possess in-house and, simultaneously, to raise a network of external partners or experts to be used on demand for specific purposes. The ability to set up dynamic networks with select partners and in-house evaluation and absorption capabilities is a requirement for success.

Geographical proximity between firms related to specific sectors or technologies has been identified as one of the critical factors to speed up innovation. Researchers have proposed that the strengthening of links facilitates knowledge transfer and sharing (Karlsson et al. 2005). Keeping strong links over time calls for stability in relationships and mutual credibility.

As a consequence of the interaction of the three challenges mentioned above, innovation is addressed by combining knowledge from several entities: from basic knowledge providers, technology developers, pilot users or specialized entities for TT or marketing activities. This is the basis for the concept of open (technical) innovation. Nevertheless, the degree of "openness" found in the open innovation realm varies from industrial sectors, geographical contexts, or involved technologies. Cooperative frameworks, as an evolution of more traditional bilateral or soft networking schemes, should be stable enough to reach the mutual credibility to facilitate long-term partnerships in technology transfer.

Today, three types of open innovation models can be identified in business sectors: subcontracted, cooperative, and open community models. Notice that these approaches are compatible and that all of them could coexist in a given scenario. These approaches will be described from the TT perspective in next sections.

\subsection{Subcontracted Innovation Model}

Within the subcontracted innovation model, research and development needs for specific purposes of a company (acting as contractor) are totally or partially subcontracted to another company or to one public research center or university. This corresponds to the well-known model of contract research widely used by companies in past decades.

This case is characterized by a strong asymmetry between the client and the provider of the required knowledge. All property and exploitation rights of the subcontracted 


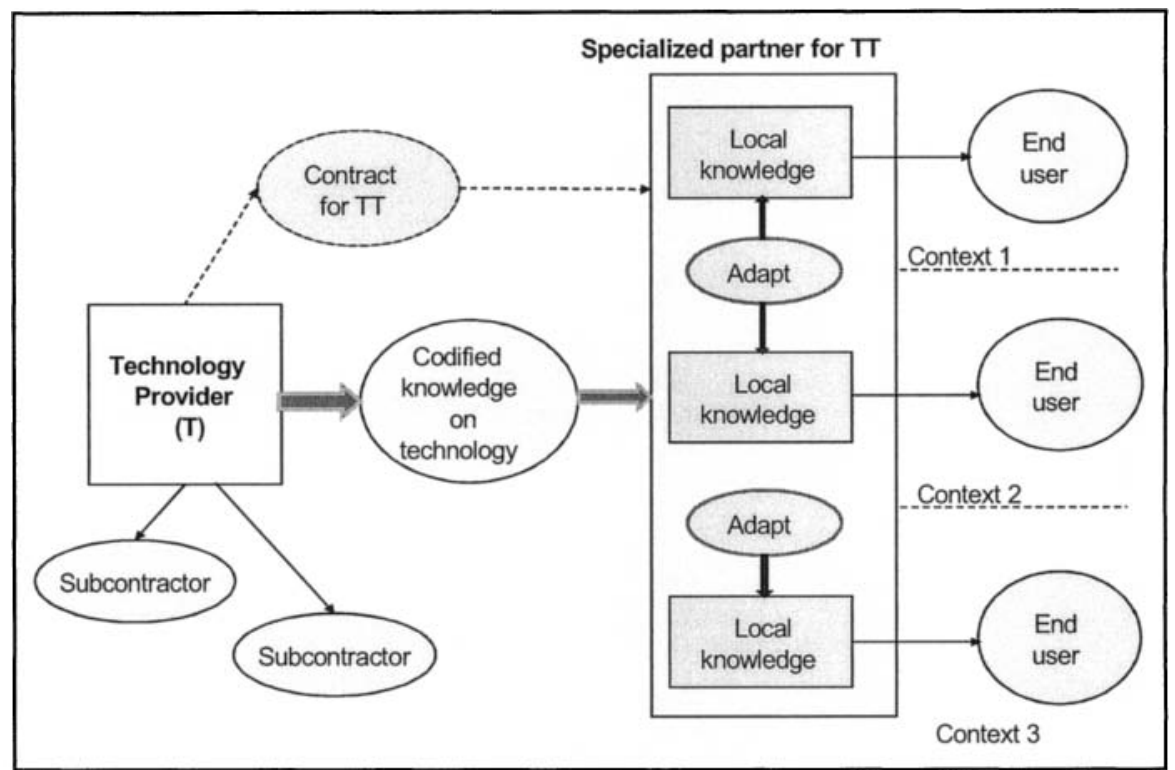

Figure 1. Subcontracted Innovation Model

activity lie with the contractor company with the exception of legal provisions in intellectual property legislation. If subcontractors are properly identified (in some cases or industrial sectors after a prequalification process), the three challenges defined above are addressed. Usually, multidisciplinarity requires signing several contracts with one or more entities.

The weakest point for this approach is the need to define in detail the components to be subcontracted in order to agree on time and money between parties. It precludes technological breakthroughs or, at least, very innovative solutions because subcontracted entities do not like to risk their contracts looking for solutions that are not clear. Furthermore, system integration and commercialization risks remains with the contractor. Again, this sharp distribution of roles and responsibilities is a constraint for innovative solutions.

It is theoretically possible to extend this model to cover technology transfer activities if developers rely on subcontracted, specialized entities to perform the transference activities in specific sectoral or geographical contexts. In practice, this model only works with very mature technologies when knowledge related to the target technology can be perfectly codified to be transferred to the specialized subcontracted unit. The extreme case is to agree on preexisting commercial structures for TT or diffusion. Figure 1 graphically depicts these interactions.

Notice that the technology provider does not have direct contact with end users. The specialized partner for TT (only one is represented in Figure 1) should have the necessary local knowledge to be able to have contact with end users in different contexts and to communicate feedback from the users to the provider. This structure is compatible with the use of other subcontractor entities during the technology development phases. 


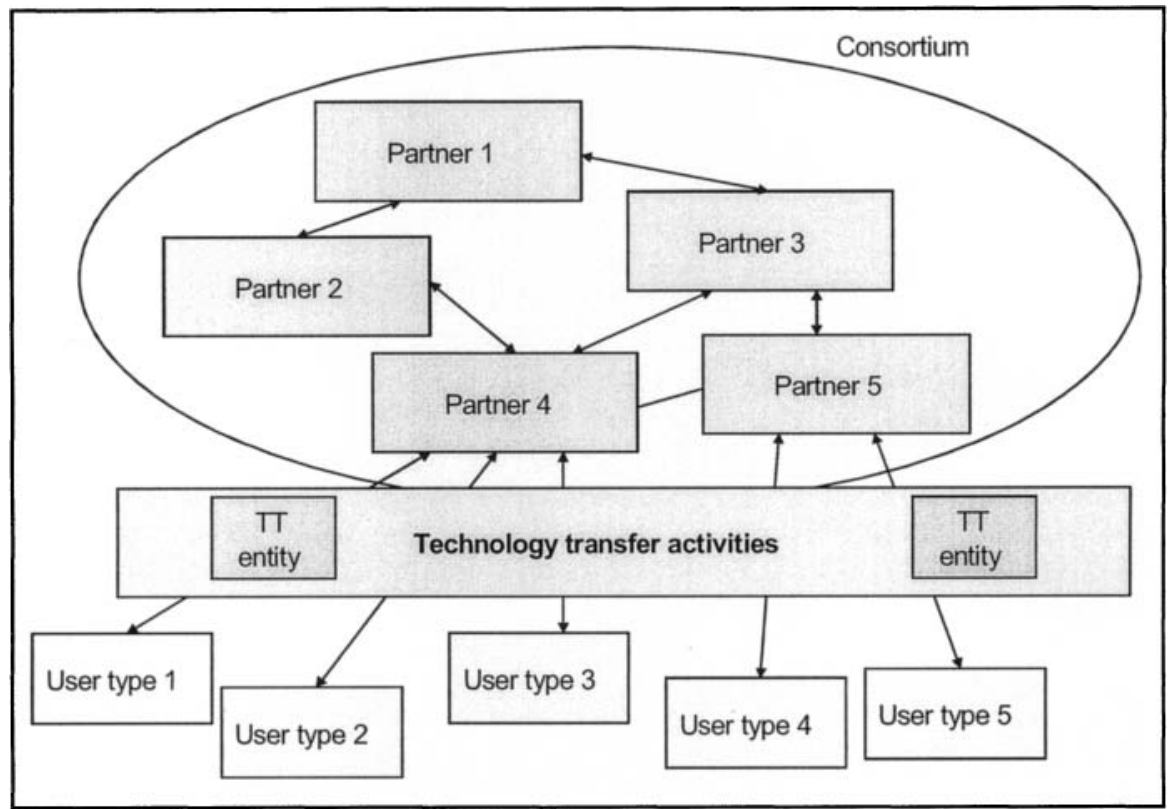

Figure 2. Cooperative Innovation Model

\subsection{Cooperative Innovation Model}

The cooperative innovation model is based on the need to share knowledge, risks, and benefits among a set of individual partners, both public and private. The set of partners agreeing to join forces to address a specific goal is called a consortium and this model is also known as consortia-based innovation. This model is widely supported by public administrations in Europe, well aware of the spillovers generated by national (or supranational) innovation systems.

Distribution of responsibilities within consortia is based on the specific scientific and technical capabilities of each partner. Usually, one partner assumes the coordinator's role while others perform specific tasks. Property and exploitation rights are also distributed on the basis of the work performed by each partner following rules approved by funding institutions. This model can also be combined with the subcontracted approach because one or more partners could have one or more subcontracted entities (up to a maximum percentage). This model has been mainly used for research and technology development activities. Figure 2 depicts the general elements and interactions associated to this model.

The application of this model to technology transfer activities is less straightforward. When TT is embedded into a larger process of technology development (as occurs in many R\&D programs), activities like pilot experiences, demonstrators, structured feedback from users, etc. are addressed by the developers themselves. If an open cooperative model is used, those entities participating in the consortium assume some TT activities by distributing responsibilities according to their background and expertise. 
In other cases, where TT is isolated from technology development due to specific complexities or lack of experience by developers, refinements of the open cooperative TT models are required. Notice that technology transfer activities are associated with some partners while others remain linked to pure technology development. As Figure 2 suggests, subcontracted specialized entities could support involved partners in carrying out TT activities; in other cases, these activities are supported by technology developers.

The weakest point for this approach is the need to ensure a good level of cooperation (even at the end of the activity) between partners to be able to exploit the results. The experience within the consortia-based approach used in the European Union advises creation of consortia structures where the role played by partners complements (but does not compete with) each other in the value chain. If cooperation among potential competitors is needed (e.g., to agree on an industry de facto standard in some technological domain), the time horizon for commercial exploitation is moved forward. Another difficulty stems from the fact that a single company cannot exploit all of the results by itself. As property rights are distributed for all involved partners, they should rely on others' interests. This constraint motivated use of this model only in cases where expected results were far from the market (historically, it was termed as precompetitive research) or when pre-agreements (even through the creation of specific legal entities) could cope with future exploitation aspects.

The full implementation of this approach of open innovation requires that governments play a more proactive role in stimulating cooperation through implementing specific policy instruments and favorable contexts. These instruments could support traditional collaborative research through individual projects, as similar instruments do in many other consortia-based R\&D programs at the national and international level.

\subsection{Open Community Innovation Model}

An innovation model less often used in industry, but well known in the academic world, is based on open patents, publications, and stimulation to others' innovative solutions. This model can be found under the umbrella of open communities. These communities are understood in an international context where potential customers access immature versions and provide feedback to developers. In this context, different entities (in many cases, SMEs and public researchers) post their solutions, looking for wide acceptance and reuse. Sometimes, they compete with other open communities adhering to other types of solutions (i.e., another hardware platform or operating system in the case of the IT sector). Benefits come from rapid evolution of the field (as more entities participate, the faster is the evolution).

Large private companies were initially reluctant to sacrifice control of their R\&D activities to gain more information, and they were not motivated to put their preexisting knowledge at general disposal. Nevertheless, given the time pressure to create markets for some types of specific products or solutions, large companies noticed that this model could dramatically increase the number of brilliant people involved in providing solutions, and the number of early customers and, ultimately, to speed up early product deployment.

Figure 3 schematically depicts the structure of this model driven by one (large) company generating a product incorporating elements contributed by several entities. 


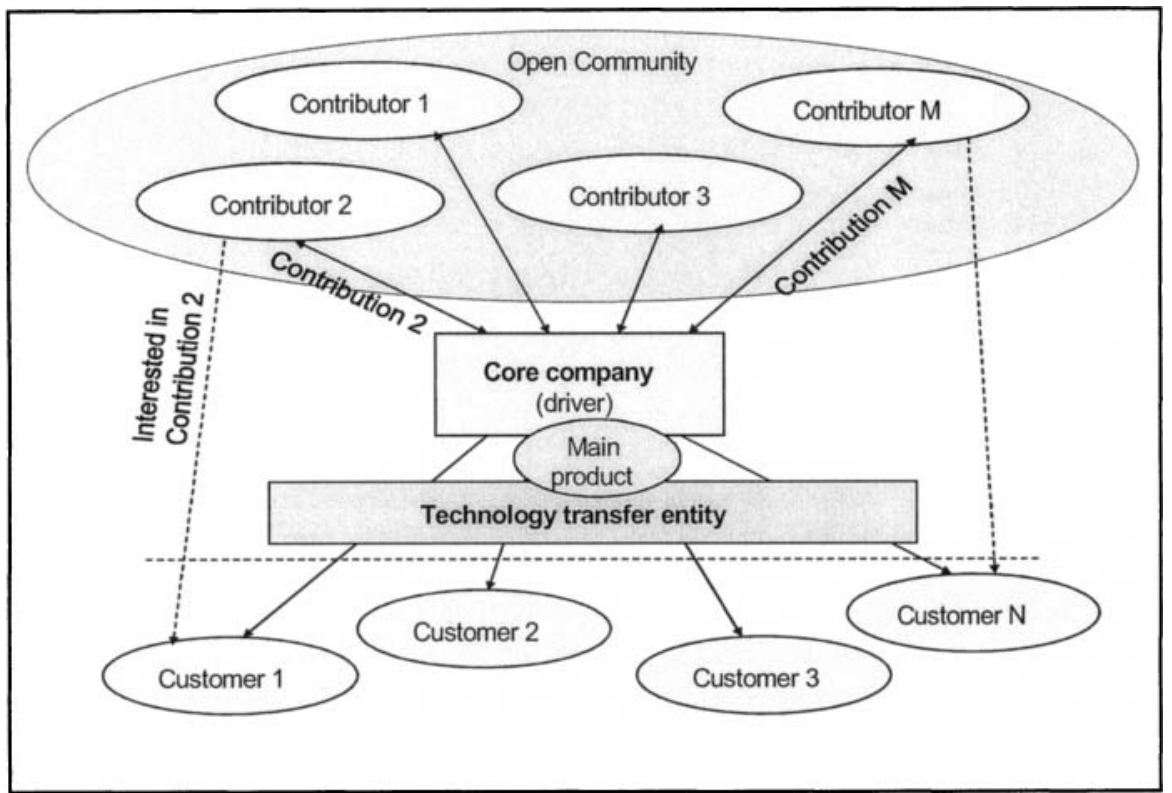

Figure 3. Open Community Model

These contributors could have a formal agreement with the core company to access the part of the technology they need if the information is open. Notice that technology transfer entities could be used or not. In this last case, the TT function is assumed by the core company or directly by some contributors (others delegate this responsibility to the core company).

\subsection{Rationale for University-Industry Open Cooperation in Technology Transfer}

Although all of the innovation models presented so far can be implemented by involving only private companies, it is becoming common to find universities and PROs involved in these kinds of partnerships. In some cases, governments have enforced this participation through regulations in policy instruments as a mechanism to increase "vertebration" in science and technology systems; in other cases, they participate because companies need to access the specialized knowledge required for specific projects.

The relationship between universities or PROs and enterprises in research activities has been deeply analyzed from several points of view in all advanced countries. Behind this interest lies recognition of its importance in building the so-called "knowledge society" by its positive impact in accelerating knowledge flows (Debackere and Veugelers 2005; Reichert 2006). The European Commission has devoted attention to this phenomenon in order to understand the strengths and weaknesses and to tune specific support policies (COM 2006a; EIRMA 2005). 
The traditional approach, where universities create scientific knowledge to be used, incorporated in products or processes, and, finally, exploited by industry, refers to a linear model of innovation that has been demonstrated useless in a complex society. The new approach of open innovation relies on public-private partnerships, knowledge sharing and mutual learning (Ormala et al. 2005). In the new approach, universities find themselves as key stakeholders in an open innovation model where industry relies more and more on advanced knowledge to survive.

Policy instruments need to move further in promoting internal reforms in universities or PROs, or, by extension, in facilitating the creation of public-private partnerships (PPP) in a more general sense. PPPs in this contribution refer to stable agreements where universities, industries, and governments contribute to the creation of a sustainable agreement to support research and innovation in a predefined field. Sustainability is understood both from time and funding dimensions; in other words, partners should commit sufficient resources for actual science and technology progress during long periods of time. The analysis of this situation reveals the need to find a different basis for stable cooperation. In this context, the EU (EIRMA 2005) promoted the development of a guide to better practices for collaborative research between science and industry.

The PRO/university-industry research cooperation based on bilateral agreements can be theoretically extended to cover TT activities where universities are ready to provide extra knowledge on the technology developed (by themselves or by other entities) and they agree to support controlled experiences of technology deployment and early training. The relevant point from the university's view is to be convinced that TT fits their mission as a public research entity when it is framed in the wider context of knowledge creation and transfer.

Industry is also looking for academic partners to support TT-related activities. For private companies, universities are needed when the technology to be transferred to third parties implies at least one of the following features:

- The knowledge on the technology to be transferred is low in the target community (first phase of its life cycle). Universities could support dissemination by participating in educational activities where they can provide specific expertise and to motivate future clients.

- There is a need to tune the technology to specificities from the target community. In this assumption, universities participating in the initial phases of technology development could modify some aspects faster than others.

- The technology needs to be complemented with other technologies or elements not available at firms as technology developers. In this context, universities could support training for selected users, create educational material, participate as advanced users (acting as qualified early adopters) by providing systematic feedback to industry, etc.

- If the technology becomes a novelty in one application field, universities can provide useful cross-experience from other domains.

From the university perspective, the main problem is not identification of the potential benefits derived from their participation in TT activities, but rather their lack of motivation because the activity is not related to knowledge generation, the primary focus of university activity (unless they could exploit the acquired knowledge by them- 
selves). To overcome this, TT activities could be embedded into conventional cooperative $R \& D$ projects or launched as complementary processes once the main $R \& D$ activities have been concluded.

The benefits of this cooperation for the involved academic entities increase when the collaborative framework is stable over time; then, is it possible to associate technology development to TT processes, to embed other knowledge-based activities, and to support future R\&D triggered by the TT evaluation. Experience shows that it is not enough unless funding agencies modify their present policy instruments. This problem will be addressed in the next section in the context of the European Union.

\section{EVOLUTION OF EU POLICY INSTRUMENTS FOR TT}

\subsection{Short-Term Instruments for University- Industry Research Cooperation}

\subsubsection{Assessment of Short-Term Instruments in the EU}

Collaborative research has evolved in Europe to support industrial policies in a number of R\&D programs like the EU Framework Program (FP) (COM 2006c), the EUREKA program, or the European Space Agency (ESA). In these cases, European countries have tried to promote intra-European cooperation among many types of European entities as a formula to speed up innovation. Due to its importance for universities, our attention will be directed at the FP instruments.

The recently completed FP6 had two different instruments for research cooperation: integrated project (IP), strategic targeted research project (STREP), and network of excellence (NoE). Universities actively participated in all of them. The single EU-FP instrument, where enterprises assume a secondary role, is the network of excellence. Within this instrument, the role of universities was even more relevant due to the type of long-term, fundamental research usually addressed in this FP instrument. In all cases, overlap between different FP instruments could occur.

All of the FP6 instruments mentioned above share a similar constraint: cooperation is limited to the duration of the $R \& D$ project $(2,3$, or 4 years as a maximum). At the end of the project, the cooperation commitments (set up by formal contracts and consortium agreements) disappear and all partners are free to decide the next step according to their interests.

\subsubsection{The Dissemination and Exploitation of Results in the FP6 Instruments}

The concepts of dissemination of results and exploitation of results correspond to two different processes.

Dissemination of results refers to the explicit will to release part of the generated knowledge by using a wide range of mechanisms like workshops, papers in journals or congresses, training activities, books, media news, etc. It is assumed that the benefit of this process is not a predefined entity but generated knowledge that will benefit any researcher or institution. 
Exploitation of results refers to the activities that partners involved in funded R\&D activities can carry out to take advantage of the investment effort in new activities with economic relevance. Usually, exploitation is done after finishing the project framed by the provisions set in consortium agreements and Commission's contract for appropriability of the generated knowledge.

- Networks of excellence (NoE) were created to speed up knowledge generation by integrating the research agenda of multiple institutions (mainly PROs). It is obvious that setting up good mechanisms to ensure open dissemination of research results is a crucial factor in the assessment of the instrument; consortia agreements need to facilitate this dissemination in specific clauses.

- Integrated projects (IP) emphasize the closed exploitation of research results in the consortium partners by using the knowledge (both scientific and technological) generated during the project. It is also clear that the role and type of the different partners in a specific project limits the capabilities to exploit the generated knowledge. Industrial partners can access better the internal know-how to transform the results into a new set of products and processes.

- Collective research projects emphasize the development of common solutions for associations or groups of SMEs. Due to the low capacity of many of these participants, the research is carried out by other public or private entities, including universities.

The last monitoring report of EU FP6 (León et al. 2006) reveals that none of the FP policy instruments with the exception of collaborative research were designed by keeping TT activities in mind, and participants in R\&D projects were not motivated to pay attention to TT and dissemination of results. However, these instruments could support some tasks related to the transference of the generated knowledge within the consortium to specific user entities in order to receive feedback and to tune the technology associated to pilot experiences. Other TT activities outside the consortium are not explicitly addressed.

Primary responsibility for the exploitation of results relies on the partners of every project, and the European Commission cannot interfere in internal agreements except when plans or commitments were explicitly included in the project tasks. FP instruments give enough capabilities to universities in using the results of their research because the participation is regulated and protected by the Commission's contract and consortium agreements where IPRs are defined by common participation rules. The case of academic partners in IPs is different than in NoEs because they assume that their concept of "exploitation" is different. The protection of the knowledge generated during the project by patents and, if possible, to licence them for industrial exploitation should be compatible with academic papers to justify their participation.

It is not common to find in IPs, STREPS, collective research, or even in NoEs too much effort (time and money) devoted to open dissemination of research results to nonexperts. Furthermore, the evaluation of the project outputs in their institutions is never likened to TT activities but to the impact of academic papers. As a consequence, even when dissemination is addressed, it is understood as "peer dissemination" (to experts in the field) because personal promotion and recognition could depend on it. As a consequence, participants in FP6 do not devote time or effort to open dissemination of their work to nonexperts. 


\subsection{Long-Term Instruments for University- Industry Research Cooperation}

Public administrations are convinced that the creation of stable university-industry relationships will facilitate the adaptation of the research agendas of public research groups to industry needs if this evolution is economically supported during long periods of time (COM 2006c). Simultaneously, enterprises will be more prone to demonstrate or incorporate advanced technology in their products or processes if the link to the science base is stable enough to allow feedback and adaptation. Behind it, public administrations have another objective in mind: to boost private investments in innovation by cofinancing a whole range of activities.

The consequence is the design of new policy instruments oriented to support longterm joint research ventures. The emphasis is not placed on the cooperation for one specific R\&D project but the support for a wider research line during long periods of time with higher commitments of involved institutions. Over the years, many specific R\&D projects and other activities (technology watch, post-graduate education, mobility, and technology transfer and diffusion) can be launched within the scope covered in the research line.

Looking for more stable PPPs, the EU promoted another mechanism: European technology platforms (ETPs). An ETP is a soft but long-term instrument led by European industries proposed during the execution of FP6 and in the preparation of FP7. The objective was to join a set of public and private institutions to agree on a long-term strategic research agenda (SRA) of up to 20 or 30 years and its associated roadmap in one specific domain. As a measure of the success, 36 ETPs were launched at the end of 2006. Notice that this instrument reinforces the role of industry in driving the research agenda.

The influence of ETPs heavily depends on their capability to attract all major stakeholders (basically, large industries) and other knowledge-intensive partners. Although resources are available to coordinate activities, the commitment of participants is not very hard. Nevertheless, there is a clear opportunity for participants to identify specific R\&D projects and to receive funds by using other short-term instruments. Several European countries are creating national technology platforms as mirrors of the EPTs to address more local needs. Knowledge transfer is assured though public documents.

Universities assume a secondary role in ETPs because the leadership in SRA elaboration comes from large industries, but agreement on a common research agenda is a very important result to ensure that public and private entities will work in the same direction and facilitate TT in later stages.

Table 1 summarizes the main features of the instruments used in FP6 (including ETPs) affecting TT activities.

Figure 4 graphically represents the range of possibilities used today by universities to facilitate long-term agreements with industry: from the location of private research centers (usually in combination with some agreements to exploit technology created by the university) in their own premises, to well-known contract-research activities to research groups, to the exploration of other more innovative approaches like the temporal use of space in university research centers for specific activities or the creation of permanent joint legal entities (foundations, common enterprises, economic interest grouping, etc.). 
Table 1. Summary of Features of Short-Term Policy Instruments in the EU

\begin{tabular}{|l|l|l|l|l|l|l|}
\hline & & & & & \\
\hline $\begin{array}{l}\text { Type of } \\
\text { contract }\end{array}$ & $\begin{array}{l}\text { Subcontract } \\
\text { to one partner }\end{array}$ & Partner & Partner & Partner & Partner & associate \\
\hline IP regime & $\begin{array}{l}\text { Owned by } \\
\text { contractor }\end{array}$ & $\begin{array}{l}\text { Shared by } \\
\text { Partners }\end{array}$ & $\begin{array}{l}\text { Shared by } \\
\text { Partners }\end{array}$ & $\begin{array}{l}\text { Shared by } \\
\text { Partners }\end{array}$ & Shared by & None \\
partners
\end{tabular}

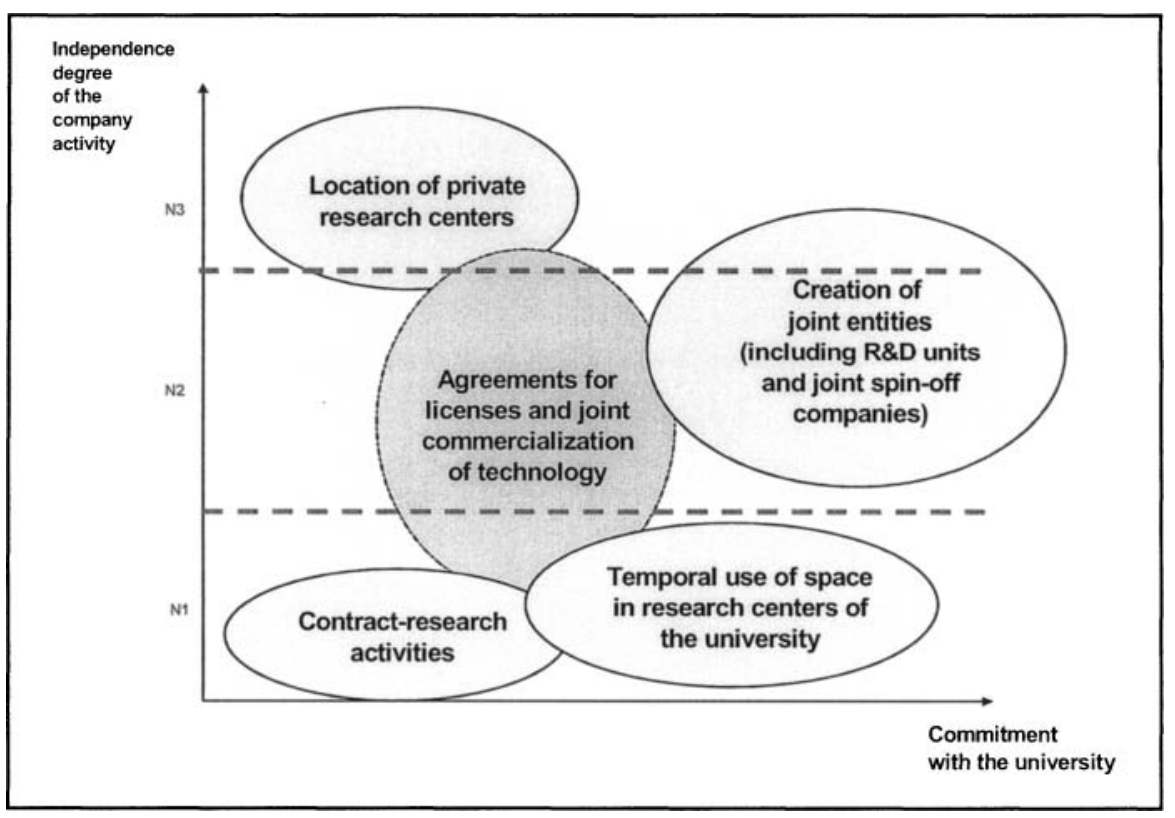


In this context, joint research centers are the most useful mechanism to embed R\&D and TT activities and are described as follows. A joint research center implies the creation of a common research infrastructure located within university premises to develop R\&D activities closely linked to the interest of the enterprise (less common in other types of PROs). In some cases, more than one enterprise participates in the research center. The agreements imply long-term funding of a limited number of research lines which are decided with a strong influence of the enterprise. Indirectly, they try to boost more in-house research in the industrial sector. The creation of these entities is complemented through specific agreements on TT, dissemination, and exploitation of research results. European governments (both central and regional authorities) have defined support policies with specific funding for university-driven science parks where the location of some research institutions near potentially interested industries was also promoted to facilitate both explicit and tacit knowledge transfer.

Large multinational companies strongly supporting open innovation drive the creation of networks of joint (or supported by long-term agreements) research centers in several European countries. The effect is the need for a better complementarity in research topics and less dependence on funding from national or regional industries. These networks could have several levels of interdependence, but in a decade many excellent teams/centers could be involved in these ventures.

In this rich context, the EU has proposed the creation of the European Institute of Technology (EIT) (COM 2006c). The rationale behind it is based on the recognition by the European Council that

a European Institute of Technology-based on top-class networks open to all Member States-will be an important step to fill the existing gap between higher education, research and innovation, together with other actions that enhance networking and synergies between excellent research and innovation communities in Europe.

EIT is proposing to fund the so called knowledge communities, where specific institutes or research groups belonging to one university with other external academic and business partners propose the creation of one of these communities.

\section{A CASE STUDY FROM THE INFORMATION TECHNOLOGIES}

The analysis made in previous sections can be applied, in principle, to any scientific and technical domain. Nevertheless, the domain of technologies for the information society presents some features that made the use of open innovation models for TT activities relevant. For the purposes of this paper, five features are relevant.

1. The open development of information technologies by a set of entities linked by strategic alliances is even more common than in other domains due to time-to-market pressures. The pace of introduction of new products or services is much faster than in other fields due to fierce competition, the pace of technical obsolescence, and the small window of time opportunity for a specific product. 
2. Multidisciplinary approaches, especially in the deployment of telecom services, require early feedback from advanced users and the participation of different entities due to knowledge fragmentation, which increases the need to access, integrate, and consolidate external knowledge inside IT entities.

3. Entry barriers to innovation are lower than in other industrial sectors where capital investments are very high to obtain first results. This feature provokes a dynamic networking where ideas, people, and (immature) solutions are integrated looking for market anticipation. Cluster structures where private and public entities work closely together seem also adequate to facilitate rapid exchange of ideas.

4. The deployment of new IT services requires systematic feedback from end-users, who can accept high degrees of instability compensated by the access to very immature technologies. Academic entities play an important role in this area.

5. At the national and European level, IT is an exploratory field for testing new policy instruments to boost competitiveness: open public procurement models, national or supranational regulations concerning frequency allocation, property rights enforcement, or licenses linked to geographical deployment.

As a consequence of these features, the IT sector perceives the need of cooperation in a more acute way, promoting a close link betgween technology development, transfer, and diffusion. Although all open cooperative models are used, the IT sector offers several examples of success in using the open community models due to the possibility to rapid exchange of knowledge and solutions which contribute to the generation of software packages (i.e., in games, operating systems, specialized libraries, etc.) for a specific hardware or software platform or the deployment of advanced services. This approach is difficult to implement in physical (or hardware) product developments.

Universities and PROs can assume an innovative role due to the need to transfer and diffuse IT solutions to advanced users (mainly from academia) even in immature phases and also to give feedback to commercial equipment providers. Simultaneously, the emergence of a commercial market can be speeded-up based on the accumulated experience. In this context, open cooperative approaches with long-term public-private partnerships are common with the strong involvement of public authorities.

An example of advanced IT service deployment with a strong emphasis on TT is the deployment of massive grid-based services. Grid technology is a second step on top of the academic research networks deployed in the last two decades. Here, the need to access to huge supercomputers with massive data storage to conduct research in basic science (particle physics, climate change, structural biology, etc.) made cooperation with other entities for long periods of time necessary. From the service standpoint, maturation speed depends on the capability to transfer it in controlled scenarios. Notice that the required infrastructure for grid service deployment is based on high-speed networks and supercomputer pre-commercial equipment. Figure 5 summarizes the role played by the involved stakeholders.

Both national and European authorities have stimulated the deployment of highspeed academic research networks and grid services by financing investments and recurrent costs of the provision of grid services. Furthermore, the communications costs are 


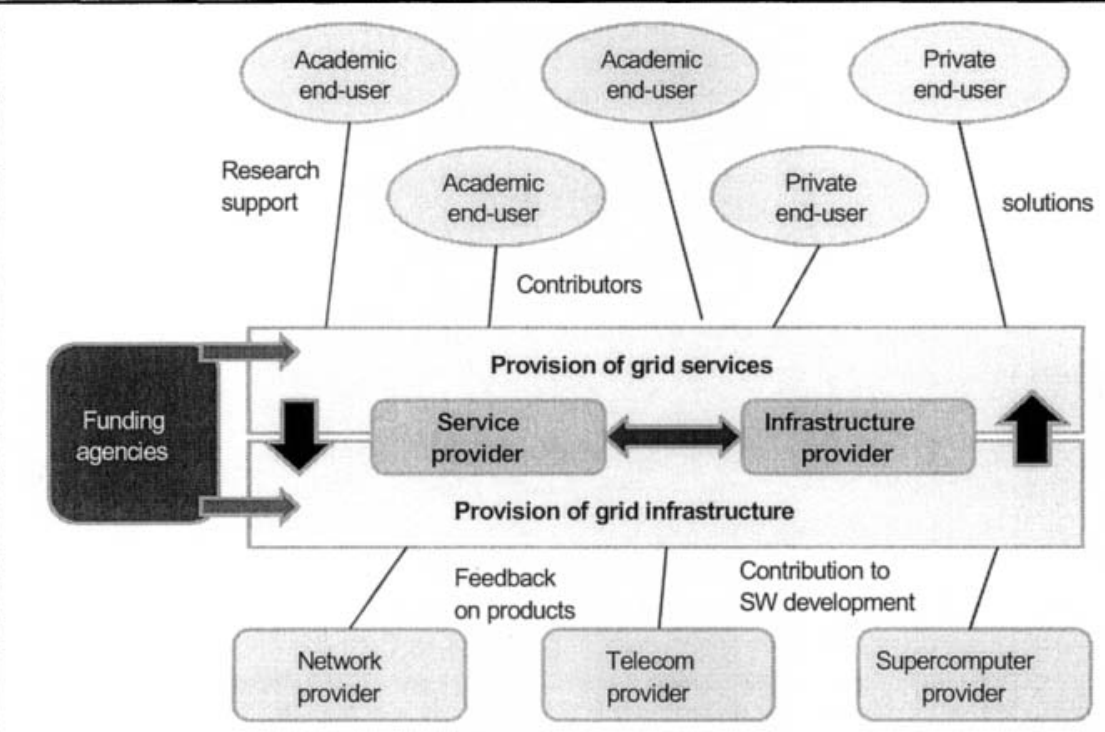

Figure 5. Grid Services from the TT Perspective

also partly supported for not-for-profit institutions. As an example of research-driven public procurement, it also triggered cooperation with the private sector by assuming that academic entities would accept a reasonable level of instability compensated by lower costs and experimentation capability. Universities, apart from their capability to offer advanced technical solutions (i.e., in network management, new generation of services, etc.), also participate as advanced users and help others (public and private) entities to adopt services.

Table 2 summarizes the characteristics of this case from the open cooperative models standpoint, where the evolution of embedded academic research networks is also presented as a hidden technology. Notice the coexistence of some of them.

The participation of large telecommunications and computer companies is also essential because public entities do not possess the capability to implement a large supercomputer or to deploy an optical network. Participation of universities and public research centers was more focused on providing middleware solutions for specific purposes and the use of new services. This is a good example of TT embedded into technology development with the strong participation of advanced users.

The involvement of users from the private sector (at the first stage, participation was carried out through research departments but other engineering departments were progressively involved) offers another possibility to increase public-private cooperation. In this sense, the possible use of the academic network by private companies involved in FP consortia-based R\&D projects is an example. The same situation is happening in the grid field.

Two levels of openness in cooperation can be identified. This case can be classified as a cooperative one with strong involvement of users (scientists) to provide the technological basis on top of high-speed networks. Simultaneously, the strong presence 
Table 2. Open Cooperative Examples in the European TT Sector

\begin{tabular}{|c|c|c|}
\hline Feature & $\begin{array}{l}\text { Embedded Academic } \\
\text { Research Network }\end{array}$ & Grid Technology \\
\hline $\begin{array}{l}\text { Open innovation } \\
\text { models used }\end{array}$ & $\begin{array}{l}\text { Subcontracted } \\
\text { Cooperative }\end{array}$ & $\begin{array}{l}\text { Extension of the open community } \\
\text { models limited to public } \\
\text { communities }\end{array}$ \\
\hline $\begin{array}{l}\text { Technology } \\
\text { maturation }\end{array}$ & $\begin{array}{l}\text { Moderate maturity level in net- } \\
\text { works, but both immature and } \\
\text { mature services }\end{array}$ & $\begin{array}{l}\text { Immature, both in basic com- } \\
\text { ponents and in services }\end{array}$ \\
\hline $\begin{array}{l}\text { Involvement of } \\
\text { universities and } \\
\text { public research } \\
\text { centers }\end{array}$ & $\begin{array}{l}\text { Deep involvement at the beginning } \\
\text { but responsibility was } \\
\text { progressively transferred to } \\
\text { specialized organizations }\end{array}$ & $\begin{array}{l}\text { Yes, from the beginning until } \\
\text { today; this role will be lower when } \\
\text { technology matures }\end{array}$ \\
\hline $\begin{array}{l}\text { National } \\
\text { governmental } \\
\text { support }\end{array}$ & $\begin{array}{l}\text { Communication costs } \\
\text { Support to R\&D projects access }\end{array}$ & $\begin{array}{l}\text { Infrastructures costs like super- } \\
\text { computers or data management } \\
\text { Support to R\&D projects }\end{array}$ \\
\hline European support & $\begin{array}{l}\text { International communication costs } \\
\text { FP development of advanced } \\
\text { services }\end{array}$ & $\begin{array}{l}\text { Use of academic research } \\
\text { networks } \\
\text { Support to FP projects } \\
\end{array}$ \\
\hline Instruments used & $\begin{array}{l}\text { National R\&D programs } \\
\text { FP infrastructures, FP IP } \\
\text { Public procurement }\end{array}$ & $\begin{array}{l}\text { National R\&D programs } \\
\text { FP } \\
\text { Public procurement }\end{array}$ \\
\hline Embedded TT & $\begin{array}{l}\text { Not in network technologies } \\
\text { Yes in advanced services }\end{array}$ & Yes in grid technologies \\
\hline $\begin{array}{l}\text { Training and } \\
\text { education approach }\end{array}$ & Not covered & $\begin{array}{l}\text { Yes. User training covered in } \\
\text { formal seminars }\end{array}$ \\
\hline $\begin{array}{l}\text { Public-private } \\
\text { partnership }\end{array}$ & $\begin{array}{l}\text { Yes, it derives from conditions in } \\
\text { public procurement }\end{array}$ & With large multinationals \\
\hline User's participation & $\begin{array}{l}\text { Organized feedback to network } \\
\text { operators } \\
\text { User do not need to have a } \\
\text { technical background }\end{array}$ & $\begin{array}{l}\text { Organized distribution of } \\
\text { responsibilities } \\
\text { Technical users or scientists }\end{array}$ \\
\hline $\begin{array}{l}\text { Co-ordination } \\
\text { structures }\end{array}$ & $\begin{array}{l}\text { Yes, well structured at the national } \\
\text { and European levels }\end{array}$ & $\begin{array}{l}\text { Yes, based on a hierarchical } \\
\text { structure for data management and } \\
\text { access }\end{array}$ \\
\hline
\end{tabular}

of academic entities offers the co-existence with an open community model in the use of data once the technology has matured to emphasize services to scientific end users. It is still too early to extend it to other commercial users.

\section{CONCLUSIONS}

Governments and universities should work together to foster closer cooperation with private entities in the framework of open innovation models to increase knowledge 
generation, transfer, and use. Although all types of innovation models as presented in this paper are potentially useful, the right choice depends on the context, degree of maturity of the technology, and specific reward mechanisms from public administrations to stabilize long-term cooperation. A general trend characterized by an increasing involvement of universities in the participation of consortia-based policy instruments, where cooperation with industry is not restricted to specific research projects but applied in wider schemes, is noticed. A deeper institutional involvement of public universities has also permitted extending the range of TT cooperation between public and private sectors by assuming the role of advanced users. The growing management autonomy of public universities in the EU can facilitate the definition and implementation of new instruments adapted to their specific context without relying exclusively on instruments defined by public administrations.

Policy instruments provided by public administrations are also moving toward funding long-term partnerships because benefits cannot be obtained in the relatively short period of one $R \& D$ project, dissemination and exploitation is difficult to address in this context. The analysis of short-term and long-term instruments available in the EU for university-industry cooperation reveals a richer realm where many different approaches coexist and coevolve over time. The EU FP6 also promoted this change of trend with new participation instruments for a broader concept of innovation where education, research, and transference can be simultaneously addressed.

The sector of information technologies has been used as a pilot field due to the need to increase cooperation to speed up the deployment of advanced services. The case of grid technology and services demonstrates the usefulness of using cooperative open innovation models within the triple helix paradigm at the international level and the need to embed TT activities as a part of immature service deployment processes.

\section{References}

Albino, V., Carbonara, N., and Giannocaro, I. "Industrial Districts as Complex Adaptive Systems: Agent-Based Models of Emergent Phenomena," in C. Karlsson, B. Johansson, and R. R. Stough (eds.), Industrial Clusters and Inter-firm Networks: New Horizons in Regional Science, Cheltenham, UK: Edward Elgar, 2005.

COM. Delivering on the Modernization Agenda for Universities: Education, Research and Innovation, Brussels: Commission of the European Communities, 2006a (available online at http://ec.europa.eu/education/policies/2010/doc/comuniv2006 en.pdf).

COM. Implementing the Renewed Partnership for Growth and Jobs:- Developing a Knowledge Flagship: The European Institute of Technology, Brussels: Commission of the European Communities, 2006b (available online at http://eur-lex.europa.eu/LexUriServ/site/en/com/ 2006/com2006_0077en01.pdf).

COM. Proposal for a Regulation of the European Council and Parliament Establishing the European Institute of Technology, Brussels: Commission of the European Community, 2006c.

Debackere, K., and Veugelers, R. "The Role of Academic Technology Transfer Organizations in Improving Industry Science Links," Research Policy (34:4), April 2005, pp. $321-342$.

EIRMA. Responsible Partnering: Joining Forces in a World of Open Innovation. A Guide to Better Practices for Collaborative Research between Science and Industry, Paris: EIRMA, in cooperation with EUA, Pro Ton Europe, and EARTO, January 2005 (available online at http://www.eirma.asso.fr/f3/local_links.php?action_jump\&id=796). 
Etzkowitz, H., and Leysderdoff, L. "The Dynamics of Innovation: From National Systems and 'Mode 2' to a Triple Helix of University-Industry-Government Relations," Research Policy (29:2), 2000, pp. 109-123.

Foray, D. (rapporteur). "Globalization of R\&D: Linking Better the European Economy to 'Foreign' Sources of Knowledge and Making EU a More Attractive Place for R\&D Investment," Grupo de expertos de la Comisión Europea "Knowledge for Growth," April 2006.

Geroski P. A. "Models of Technology Diffusion," Research Policy (29:4-5), April 2000, pp. 603625.

Karlsson, C., Johansson, B., and Stough, R. R. (eds.). Industrial Clusters and Inter-Firm Networks: New Horizons in Regional Science, Cheltenham, UK: Edward Elgar, 2005.

León, G. (Chairman), Calzarossa, M. (Rapporteur), Goericke, D., Olesky, E., Rogerson, S., Schmidt-Lainé, C., and Timperi, A. "Monitoring Report 2005: Implementation of Indirect Research Activities of the Sixth Framework Programmes of the European Community (EC) and the European A tomic Energy Community (EURATOM), October 2006 (available online at http://polaris dit.upm.es/ gonzalo/Monitoring2005.pdf).

Ormala, E. (Chairman), Vonortas, N., Ayme, S., Cok, L., Donnelly, D., King, J., Mandl, C., Meyer-Krahmer, F., Llesky, E., Quintanilha, A., Stame, N., Tarrach, R., and ThysClement, F. "Five Years Assessment of the EU Framework Programme (1999-2003)," European Commission, 2005 (available online at http://ec.europa.eu/research/reports/ 2004/fya en.html).

Reichert, S. "Research Strategy Development and Management at European Universities," European University Association, EUA Publications, Brussels, 2006 (available online at http://www.eua.be/fileadmin/user_upload/files/EUA1_documents/Research_Strategy.115 0458087261.pdf).

\section{About the Author}

Gonzalo León is Professor in the Telematics Engineering Department at the Universidad Politénica de Madrid. His research activities focus on software engineering for telecommunications systems and on information technology transfer. Since 1986, Professor León has occupied several relevant positions in the Spanish Administration of Science and Technology: as Deputy General Director for International Relations on R\&D, as Deputy General Director at the Office of Science and Technology attached to the Presidency of the Government. In 2002, he was appointed Secretary General for Science Policy at the Ministry of Science and Technology, responsible for the national $R \& D$ plan and industrial relations. He is chairman of the expert group on the follow-up of the Lisbon Strategy and vice president of the Space Advisory Group at the European Commission. Since 2004, he has served as vice president for Research at the Universidad Politénica de Madrid. He can be reached by e-mail at gonzalo.leon@upm.es. 